Original Research Paper

\title{
Development of Phage Display Technology: A Bibliometric Assessment
}

\author{
${ }^{1,2}$ Alexander Ilyichev, ${ }^{1,2}$ Larisa Karpenko, ${ }^{2,3}$ Vadim Gureyev and ${ }^{3}$ Nikolay Mazov \\ ${ }^{1}$ Altai State University, Barnaul, Russia, 656049, Russia \\ ${ }^{2}$ Vector State Research Center of Virology and Biotechnology, Koltsovo, Novosibirsk Region, Russia, 630559, Russia \\ ${ }^{3}$ Trofimuk Institute of Petroleum Geology and Geophysics, \\ Siberian Branch, Russian Academy of Sciences, Novosibirsk, Russia, 630090, Russia
}

Article history

Received: 12-11-2015

Revised: 03-01-2016

Accepted: 08-01-2016

Corresponding Author:

Vadim Gureyev

Vector State Research Center of

Virology and Biotechnology,

Koltsovo, Novosibirsk Region,

Russia, 630559, Russia

Email: GureyevVN@ipgg.sbras.ru

\begin{abstract}
The paper presents results of bibliometric analysis of papers on phage display technology written in the past 30 years. More than 2000 Scopus-indexed papers have been published in 638 journals. $73.95 \%$ papers were published by 10 most productive countries out of 58: The USA, China, Great Britain, Germany, Japan, the Netherlands, Switzerland, Italy, France and Australia. Rapid growth in scholarly output began in 1993, i.e., 8 years after discovery of phage display in 1985 and up to 2000 was equal to $26.85 \%$ per year. Later, the number of papers stabilized. In some countries, number of studies is decreasing: The USA, Great Britain, the Netherlands, Switzerland, Italy and Australia; the other countries show increase in the number of annually published papers: Germany, Japan, France and China. Average number of citations per paper in 3-year citation window is 5.09. Swiss papers are the most cited: 9.09 citations per paper, whereas Chinese papers are lowly cited ranking 2nd: 2.51 citations per paper. Results of studies on phage display are published in 11 languages with two leading ones: English (92.19\%) and Chinese (6.29\%). Biochemistry, genetics and molecular biology subject area uses phage display technology more intensively (61.04\% papers), followed by immunology and microbiology $(31.06 \%)$ and medicine $(24.09 \%)$. The core of serials published the majority of papers on phage display began to lose strong borders. Only PLoS One shows obvious growth in the number of papers describing phage display studies.
\end{abstract}

Keywords: Phage Display, Peptide Library, Bibliometric Analysis, Citation Analysis, Scopus

\section{Introduction}

In 2015 phage display technology celebrated its 30 year anniversary. In conditions of rapid changes and emergence of new achievements in biotechnology, this term seems to be sufficient to conduct retrospective analysis of phage display in order to make some conclusions and to detect further possible trends. To date, several dozens of reviews have been published showing different aspect in the use of the technique. However, there have not been any bibliometric studies on the subject. We believe, such a study can also be useful in evaluating phage display efficiency in prior years and its future applications.

The first mention of phage display is traditionally referred to the paper of J.P. Smith, for the time a researcher of Biological Department of the Missouri University: "Filamentous fusion phage: Novel expression vectors that display cloned antigens on the virion surface" published in 1985 in Science (Smith, 1985). The second paper came from Vector State Research Center of Virology and Biotechnology (Novosibirsk, Russia) in Doklady Akademii nauk USSR in 1989 and demonstrated possibility to expose foreign peptides on the surface of filamentous bacteriophage M13 using the main coat protein (Il'ichev et al., 1989). In 1985, J.P. Smith for the first time showed that polypeptides can be exposed on the surface of phage capsids. It should be noted, that in the case of correct selection of site of insertion chimeric phage particle continues to be infectious and can be reproduced in appropriate bacterial strain. Furthermore, it was 
demonstrated that phage carrying certain peptide, can be isolated from a number of phages of wild type using affine selection or biopanning (Parmley and Smith, 1988). Rotation of selection and reproduction causes formation of phage mix comprising big amount of phage particles exposing the same peptide. Application of this principle resulted in construction of large collections of chimeric phages where each phage exposed peptide that differed from other peptides, i.e., peptide phage libraries (Cwirla et al., 1990; Devlin et al., 1990; Felici et al., 1991; Scott and Smith, 1990). In theory, such peptide repertoire can serve as a source of ligands for all receptors. After isolation of phage carrying necessary ligand amino acid sequence of selected peptides is defined by sequencing of chimeric capsid genes. Comparative analysis of amino acid compound of selected peptides enables to identify consensus sequence, i.e., conservative amino acid residues necessary for binding of this receptor.

Using phage display technique specific ligands were detected for antibodies, enzymes, proteins for transmission of cell signals, surface cell receptors and non-protein molecules (carbohydrates, polymers or other surface materials, as well as DNA) (Smith and Petrenko, 1997). Affordability of experiments and availability of affine selection technique enabled phage display to become significant tool in molecular biology, especially in the field of protein engineering and functional genomics.

Objectives of this paper are the following:

- To analyze phage display papers at the level of publication types, languages, countries of studies, subject areas and journals

- To reveal rate of citations and their distribution according to countries and subject areas

- To detect the most frequent keywords in phage display publications to precise themes of studies using phage display technology

- To reveal trends in phage display technology development globally and in certain countries using the data concerning research output, citation impact and their ratios

Detailed data are shown for 10 most productive countries studying phage display and using the technology.

\section{Materials and Methods}

To carry out bibliometric analysis international multidisciplinary database Scopus was used (Scopus, 2015). Query "phage display" was conducted in Document search tab using Article Title field. Analyzed period includes papers published from 1985 (year of the 1 st article) to 2013. Papers of 2014 were excluded due to incomplete data in Scopus by the time this work was being carried out.

We did not refine search results using any subject areas or document type restrictions; thus, all Scopus databases and all types of papers were considered. To study subject distribution of papers over disciplines Scopus Subject Areas were used. When addressing citation count, 3-year citation window was considered: The year of publication and two following years. This paper methodology was partially based on approaches offered by (Gupta et al., 2015).

\section{Results and Discussion}

\section{Phage Display Research Output}

From 1985 to 2013, researchers published 2194 Scopus-indexed papers directly devoted to phage display technology. Figure 1 demonstrates distribution of scholarly output across a date of publishing.

Figure 1 shows almost 10-year timeout between the 1st paper in Science describing new technology and the beginning of rapid growth in the number of research papers. Interestingly, this paper was unnoticed for the initial few years. Having been cited almost 2000 times by 2015 , Smith's article was firstly cited only 3 years after its publishing.

It should be noted that phage display technology was developed concurrently in the USA and in Russia at Vector State Research Center of Virology and Biotechnology. Later publishing date (1989) of the Russian paper (Il'ichev et al., 1989) can be explained by blackout of Vector's studies. From the late 1980s onwards researchers have published 24 papers on phage display technology affiliated with SCR VB Vector. Total number of papers published by Vector's researchers exceeds 100; a lot of them are affiliated with foreign organizations due to emigration of Russian scientists in the early 1990s. This list includes highly cited papers with some papers published in co-authorship with founder of technology J.P. Smith.

Significant increase in phage display scholarly output began in 1993 when Elsevier's Gene published the issue devoted to the new technology. The journal covered proceedings of the conference held in Cold Spring Harbor, USA, by J.P. Smith. After that, the term "phage display" came into scientific use, although its first mention date from the early 1980s. From 1993 to 2000, high steady growth in the number of papers on numerous aspects of phage display was observed. Annual average growth in the number of publications in that 7 -year period achieved $27 \%$. Since 2000 s, the technology has firmly established itself in a number of biomedicine areas and steadily used by researchers worldwide according to low equal fluctuations in the number of papers. 


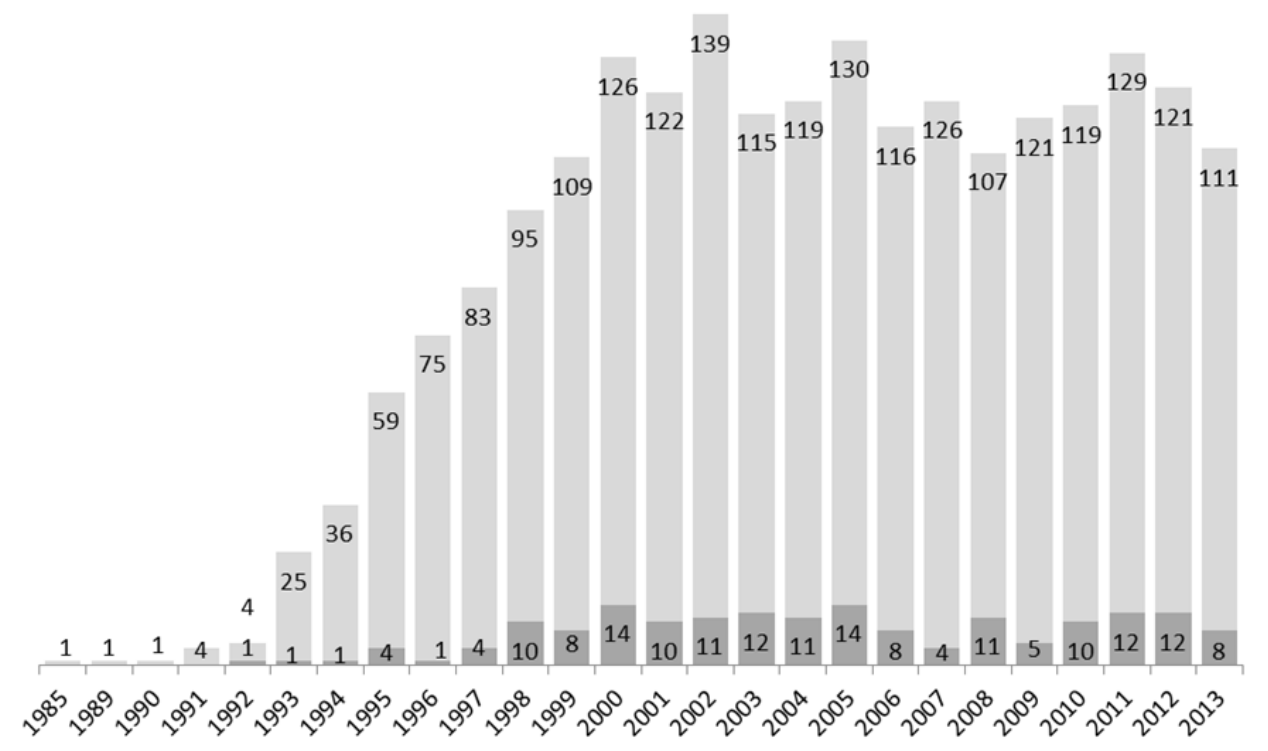

Fig. 1. Distribution of papers across the years. Top numbers mean absolute number of papers (light gray) while bottom numbers point at the number of reviews (dark gray)

\section{Types of Publications}

Distribution of document types in analyzed period was the following: $1869(85.26 \%)$ articles, $172(7.84 \%)$ reviews, $82(3.74 \%)$ conference papers, $22(1 \%)$ erratums and $22(1 \%)$ short surveys. Interestingly, this distribution lacks book chapters, letters, notes, editorials, or business articles. Reviews ranked the 2 nd next to articles; Fig. 1 shows incomplete correspondence in the number of reviews and articles that possibly points to insufficient amount of reviews.

\section{Distribution of Languages of Research Papers}

Studies on phage display were published in 11 languages:

- English-2021 papers (92.19\%)

- Chinese-138 papers $(6.29 \%)$

- Russian-11 papers $(0.50 \%)$

- Japanese-11 papers $(0.50 \%)$

- French-5 papers $(0.22 \%)$

- Korean-3 papers $(0.13 \%)$

- Portuguese-2 papers $(0.09 \%)$

- Finnish, German and Polish-each published one paper $(0.04 \%)$

It should be noted that list of the most usable languages is inconsistent with distribution of papers across countries. For instance, only one paper was published in German, although total number of papers written by German researchers is 165 . There were no papers in Italian; however, Italy is in the top 10 countries according to the number of papers on phage display. At the same time Russian ranks third according to paper count and the majority of papers from Russia is written in Russian; however, the Russian Federation is absent in the top list of countries. This phenomenon can be explained by the fact that many scientists from Vector State Research Center of Virology and Biotechnology emigrated in the early 1990s into European countries and the USA. In these countries, Russian researchers began to indicate their new affiliations in their paper on phage display causing increase in bibliometric indexes in new organizations.

When analyzing language distribution, it is necessary to consider language bias in international bibliometric databases and their focus on English that was described in a number of studies (Archambault et al., 2005; Leydesdorff and Milojević, 2014). For instance, query "phage display" in the Russian Science Citation Index (RSCI, 2015) in analyzed period delivers 148 papers, although Scopus indexes only 16 Russian papers. Such great difference is explained not only by small number of Russian journals indexed in Scopus (332 items in 2014 (LRJIS, 2014)), but also by the fact that several Russian journals with translated English version de jure belong to other countries gaining author rights. Thus, a part of Russian papers belongs to other countries. Such inconsistencies cannot significantly affect statistical data in countries with big number of papers, but they can influence in case of countries with small number of publications. Of note, in the last few years Scopus covers more than $55 \%$ of all published Russian papers (Gureyev and Mazov, 2013). At the same time, archival part of papers is weakly covered. 


\section{Citation Count}

Total number of citations of 2194 papers using 3-year citation windows is 11,176 . Table 1 shows distribution of citations across the years, as well as average number of citations per paper in a certain year.

Citation count lacks of significant leaps or dramatic fluctuations across years. The highest values of citations per paper were observed in the initial years of development of phage display technology, i.e., 1991, 1994 and 1996. Significant share in high values of citation count in those years accrues to a smaller part of the highly cited papers in some cases with 1000 or more citations. As a rule, they are reviews or papers in multidisciplinary journals with high impact factors. For example, in 1991 two of four papers were published in Nature and Nature Biotechnology; in 1994 only one paper in Annual Review of Immunology gained 22\% citations; in 1996 the most cited papers were published in Nature, Science, Nature Biotechnology and Proceedings of the National Academy of Sciences of the United States of America.

At the bottom of Table 1 distribution of publications and citations across the three 7-years periods is shown, starting from 1993 when consistent increase in paper count began. Presented data enable to conclude that during the 1 st period phage display was theoretically explained and methodological basis of its application was developed. Peak of practical application was observed in the early 2000s. After that, phage display technology can be considered as a common tool in biotechnology, since in certain periods a slight decrease in paper count was registered and citedness of papers declined. There has been lack of breakthrough discoveries in this technology, according to slowing down the rate of citedness since 2000s.

The total number of citations of 2194 papers in 2015 is 50,645. One paper is cited at average 23.10 times. Furthermore, near $20 \%$ all citations accrues to only 19 highly cited papers published in 1990s in multidisciplinary journals with high impact factors. Detailed distribution of citations is shown in Table 2.

Table 2 demonstrates that papers on phage display are highly cited, since there is lack of uncited papers and there are many papers with more than 50 citations.

\section{Distribution of Scholarly Output over Subject Areas}

Table 3 shows data concerning the most frequent keywords in papers on phage display.

Analysis of Table 3 data enables to detect some trends in development of phage display technology. Bibliometric indicators show growing interest to peptide libraries and to the use of animals in the experiments with application of phage display technology. Significant increase in number of papers devoted to design of medicinal drugs based on phage display and studies on protein binding is shown.

The top seven subject areas (more than 100 papers per each area) according to Scopus classification system are shown in Table 4-6.

Table 4-6 demonstrate 30-year changes taking place from the discovery of phage display technique: In recent years, this technology actively used in Medicine, Chemistry and Pharmaceutics, i.e., applied significance can be observed. In contrast, in basic sciences, e.g., Immunology or Microbiology, publication and citation counts are constantly decreasing due to completion of theoretical feasibility demonstration of this technology. In the last period, ranks of groups of papers have been changed depending on subject areas: Medicine has ranked second according to publication count and Chemical Engineering has outranked Agricultural and Biological Sciences. Average citations per paper is increasing in Pharmacology, Toxicology and Pharmaceutics, Agricultural and Biological Sciences, as well as in Chemical Engineering. As for medicine papers, average citations per paper is decreasing despite significant growth in publication count.

Table 1. Distribution of citations in 3-year citation window across the years; average number of citations per paper

\begin{tabular}{|c|c|c|c|c|c|c|c|}
\hline Year & Papers & Citations & $\begin{array}{l}\text { Citations } \\
\text { per paper }\end{array}$ & Year & Papers & Citations & $\begin{array}{l}\text { Citations } \\
\text { per paper }\end{array}$ \\
\hline 1985 & 1 & 0 & 0 & 2003 & 115 & 531 & 4.61 \\
\hline 1989 & 1 & 1 & 0.33 & 2004 & 119 & 545 & 4.57 \\
\hline 1990 & 1 & 1 & 0.33 & 2005 & 130 & 599 & 4.60 \\
\hline 1991 & 4 & 73 & 18.25 & 2006 & 116 & 543 & 4.68 \\
\hline 1992 & 4 & 14 & 3.50 & 2007 & 126 & 558 & 4.42 \\
\hline 1993 & 25 & 141 & 5.64 & 2008 & 107 & 463 & 4.32 \\
\hline 1994 & 36 & 364 & 10.11 & 2009 & 121 & 404 & 3.33 \\
\hline 1995 & 59 & 464 & 7.86 & 2010 & 119 & 616 & 5.17 \\
\hline 1996 & 75 & 619 & 8.25 & 2011 & 129 & 590 & 4.57 \\
\hline 1997 & 83 & 414 & 4.98 & 2012 & 121 & 524 & 4.33 \\
\hline 1998 & 95 & 597 & 6.28 & 2013 & 111 & 265 & 2.38 \\
\hline 1999 & 109 & 762 & 6.99 & 1993-1999 & 482 & 3361 & 6.97 \\
\hline 2000 & 126 & 761 & 6.03 & 2000-2006 & 867 & 4308 & 4.96 \\
\hline 2001 & 122 & 558 & 4.57 & 2007-2013 & 834 & 3420 & 4.10 \\
\hline 2002 & 139 & 771 & 5.54 & $1985-2013$ & 2192 & 11176 & 5.09 \\
\hline
\end{tabular}


Table 2. Distribution of citations. Numbers in parentheses point at a share of papers and citations

\begin{tabular}{lll}
\hline Distribution of citations & Cited papers & $\begin{array}{l}\text { Total number of } \\
\text { citations }(1985-2015)\end{array}$ \\
\hline 0 & $297(13.55 \%)$ & 0 \\
$1-10$ & $865(39.46 \%)$ & $4040(7.98 \%)$ \\
$11-20$ & $393(17.93 \%)$ & $5783(11.42 \%)$ \\
$21-30$ & $213(9.72 \%)$ & $5321(10.51 \%)$ \\
$31-40$ & $134(6.11 \%)$ & $4621(9.12 \%)$ \\
$41-50$ & $68(3.10 \%)$ & $3076(6.07 \%)$ \\
$51-100$ & $143(6.52 \%)$ & $10143(20.03 \%)$ \\
$101-200$ & $61(2.78 \%)$ & $8258(16.31 \%)$ \\
$201-1815$ & $18(0.82 \%)$ & $9403(18.57 \%)$ \\
Total: & $2192(100 \%)$ & $50645(100 \%)$ \\
\hline
\end{tabular}

Table 3. The most frequent keywords in papers on phage display. Share of papers with corresponding keyword is shown in parentheses

\begin{tabular}{|c|c|c|c|c|}
\hline \multirow[b]{2}{*}{ Keyword } & \multicolumn{4}{|c|}{ Number of papers with certain keywords } \\
\hline & All years & 1993-1999 & 2000-2006 & $2007-2013$ \\
\hline Peptide library $\uparrow$ & 1426 & $150(31.1 \%)$ & $671(77.4 \%)$ & $604(72.4 \%)$ \\
\hline Human & 1110 & $249(51.7 \%)$ & $458(52.8 \%)$ & $400(48.0 \%)$ \\
\hline Nonhuman $\uparrow$ & 1016 & $205(42.5 \%)$ & $402(46.4 \%)$ & $404(48.4 \%)$ \\
\hline Amino acid sequence $\downarrow$ & 962 & $246(51.0 \%)$ & $393(45.3 \%)$ & $318(38.1 \%)$ \\
\hline Bacteriophage $\downarrow$ & 903 & $314(65.1 \%)$ & $317(36.6 \%)$ & $259(31.1 \%)$ \\
\hline Animals $\uparrow$ & 761 & $146(30.3 \%)$ & $307(35.4 \%)$ & $306(36.7 \%)$ \\
\hline Controlled study $\uparrow$ & 719 & $85(17.6 \%)$ & $309(35.6 \%)$ & $325(39.0 \%)$ \\
\hline Molecular sequence data $\downarrow$ & 707 & $235(48.8 \%)$ & $269(31.0 \%)$ & $198(23.7 \%)$ \\
\hline ELISA & 611 & $123(25.5 \%)$ & $256(29.5 \%)$ & $232(27.8 \%)$ \\
\hline Peptide $\uparrow$ & 581 & $79(16.4 \%)$ & $235(27.1 \%)$ & $266(31.9 \%)$ \\
\hline Molecular cloning $\downarrow$ & 523 & $153(31.7 \%)$ & $217(25.0 \%)$ & $125(15.0 \%)$ \\
\hline Protein binding $\uparrow$ & 491 & $68(14.1 \%)$ & $201(23.2 \%)$ & $222(26.6 \%)$ \\
\hline Unclassified drug $\uparrow$ & 488 & $30(6.2 \%)$ & $193(22.3 \%)$ & $264(31.7 \%)$ \\
\hline Mice $\uparrow$ & 450 & $89(18.5 \%)$ & $171(19.7 \%)$ & $188(22.5 \%)$ \\
\hline Monoclonal antibodies $\downarrow$ & 443 & $129(26.8 \%)$ & $185(21.3 \%)$ & $128(15.3 \%)$ \\
\hline Base sequence $\downarrow$ & 308 & $148(30.7 \%)$ & $110(12.7 \%)$ & $45(5.4 \%)$ \\
\hline Gene library $\downarrow$ & 299 & $136(28.2 \%)$ & $89(10.3 \%)$ & $72(8.6 \%)$ \\
\hline
\end{tabular}

Table 4. Distribution of papers across the subject areas

\begin{tabular}{|c|c|c|c|c|}
\hline \multirow[b]{2}{*}{ Subject area } & \multicolumn{4}{|c|}{ Distribution of papers in three periods } \\
\hline & all years & 1993-1999 & $2000-2006$ & $2007-2013$ \\
\hline Biochemistry, Genetics and Molecular Biology $\downarrow$ & $1338(61.04 \%)$ & $309(64.11 \%)$ & $515(59.40 \%)$ & $508(60.91 \%)$ \\
\hline Immunology and Microbiology $\downarrow$ & $681(31.06 \%)$ & $180(37.34 \%)$ & $277(31.95 \%)$ & $222(26.62 \%)$ \\
\hline Medicine $\uparrow$ & $528(24.09 \%)$ & $70(14.52 \%)$ & $192(22.15 \%)$ & $266(31.89 \%)$ \\
\hline Chemistry $\uparrow$ & $233(10.63 \%)$ & $22(4.56 \%)$ & $90(10.38 \%)$ & $121(14.51 \%)$ \\
\hline Pharmacology, Toxicology and Pharmaceutics $\uparrow$ & $198(9.03 \%)$ & $14(2.90 \%)$ & $82(9.46 \%)$ & $99(11.87 \%)$ \\
\hline Agricultural and Biological Sciences $\uparrow$ & $131(5.98 \%)$ & $22(4.56 \%)$ & $34(3.92 \%)$ & $75(8.99 \%)$ \\
\hline Chemical Engineering $\uparrow$ & $121(5.52 \%)$ & $12(2.49 \%)$ & $29(3.34 \%)$ & $80(9.59 \%)$ \\
\hline Total & $2192(100 \%)$ & $482(100 \%)$ & $867(100 \%)$ & $834(100 \%)$ \\
\hline
\end{tabular}

Table 5. Distribution of citation across the subject areas (3-year citation window)

\begin{tabular}{|c|c|c|c|c|}
\hline \multirow[b]{2}{*}{ Subject area } & \multicolumn{4}{|c|}{ Distribution of citations in three periods } \\
\hline & All years & 1993-1999 & 2000-2006 & 2007-2013 \\
\hline Biochemistry, Genetics and Molecular Biology $\uparrow$ & $7097(63.50 \%)$ & $2030(60.40 \%)$ & $2722(63.18 \%)$ & $2292(67.02 \%)$ \\
\hline Immunology and Microbiology $\downarrow$ & $3491(31.24 \%)$ & $1319(39.24 \%)$ & $1394(32.36 \%)$ & $763(22.31 \%)$ \\
\hline Medicine $\uparrow$ & $2209(19.77 \%)$ & $376(11.19 \%)$ & $852(19.78 \%)$ & $981(28.68 \%)$ \\
\hline Chemistry $\uparrow$ & $1206(10.79 \%)$ & $132(3.93 \%)$ & $457(10.61 \%)$ & $617(18.04 \%)$ \\
\hline Pharmacology, Toxicology and Pharmaceutics $\uparrow$ & $989(8.85 \%)$ & $58(1.73 \%)$ & $404(9.38 \%)$ & $527(15.41 \%)$ \\
\hline Agricultural and Biological Sciences $\uparrow$ & $362(3.24 \%)$ & $39(1.16 \%)$ & $94(2.18 \%)$ & $229(6.70 \%)$ \\
\hline Chemical Engineering $\uparrow$ & $619(5.54 \%)$ & $34(1.01 \%)$ & $169(3.92 \%)$ & $416(12.16 \%)$ \\
\hline Total & 11176 & 3361 & 4308 & 3420 \\
\hline
\end{tabular}


Table 6. Average number of citations per paper in different subject areas

\begin{tabular}{|c|c|c|c|c|c|}
\hline \multirow[b]{2}{*}{ Subject area } & \multicolumn{4}{|c|}{ Distribution of citations in three periods } & \multirow{2}{*}{$\begin{array}{l}\text { Uncited papers } \\
\text { All years }\end{array}$} \\
\hline & All years & 1993-1999 & $2000-2006$ & $2007-2013$ & \\
\hline Biochemistry, Genetics and Molecular Biology $\downarrow$ & 5.30 & 6.57 & 4.41 & 4.51 & $125(9.34 \%)$ \\
\hline Immunology and Microbiology $\downarrow$ & 5.13 & 7.33 & 5.03 & 3.44 & $74(10.87 \%)$ \\
\hline Medicine $\downarrow$ & 4.18 & 5.37 & 4.44 & 3.69 & $106(20.08 \%)$ \\
\hline Chemistry $\downarrow$ & 5.18 & 6.00 & 5.07 & 5.10 & $19(8.15 \%)$ \\
\hline Pharmacology, Toxicology and Pharmaceutics $\uparrow$ & 4.99 & 4.14 & 4.93 & 5.32 & $14(7.07 \%)$ \\
\hline Agricultural and Biological Sciences $\uparrow$ & 2.76 & 1.77 & 2.76 & 3.05 & $32(24.43 \%)$ \\
\hline Chemical Engineering $\uparrow$ & 5.12 & 2.83 & 5.83 & 5.20 & $11(9.09 \%)$ \\
\hline Total & 5.10 & 6.97 & 4.97 & 4.10 & $297(13.55 \%)$ \\
\hline
\end{tabular}

Table 7. Distribution of papers on phage display over the countries

\begin{tabular}{|c|c|c|c|c|}
\hline \multirow[b]{2}{*}{ Country } & \multicolumn{4}{|l|}{ Paper count } \\
\hline & Total & 1993-1999 & $2000-2006$ & $2007-2013$ \\
\hline$\overline{\mathrm{USA} \downarrow}$ & $714(32.57 \%)$ & $196(40.66 \%)$ & $281(32.41 \%)$ & $231(27.70 \%)$ \\
\hline China $\uparrow$ & $273(12.45 \%)$ & $13(2.70 \%)$ & $91(10.50 \%)$ & $169(20.26 \%)$ \\
\hline United Kingdom $\downarrow$ & $177(8.07 \%)$ & $60(12.45 \%)$ & $81(9.34 \%)$ & $35(4.20 \%)$ \\
\hline Germany $\uparrow$ & $165(7.53 \%)$ & $32(6.64 \%)$ & $73(8.42 \%)$ & $60(7.19 \%)$ \\
\hline Japan $\uparrow$ & $125(5.70 \%)$ & $21(4.36 \%)$ & $47(5.42 \%)$ & $57(6.83 \%)$ \\
\hline Netherlands $\downarrow$ & $99(4.52 \%)$ & $29(6.02 \%)$ & $50(5.77 \%)$ & $20(2.40 \%)$ \\
\hline Switzerland $\downarrow$ & $82(3.74 \%)$ & $28(5.81 \%)$ & $41(4.73 \%)$ & $13(1.56 \%)$ \\
\hline Italy $\downarrow$ & $77(3.42 \%)$ & $30(6.22 \%)$ & $27(3.11 \%)$ & $19(2.28 \%)$ \\
\hline France $\uparrow$ & $75(3.42 \%)$ & $10(2.07 \%)$ & $41(4.73 \%)$ & $24(2.88 \%)$ \\
\hline Australia $\downarrow$ & $69(3.15 \%)$ & $17(3.53 \%)$ & $29(3.34 \%)$ & $23(2.76 \%)$ \\
\hline Total $\uparrow$ & $2192(100 \%)$ & 482 & 867 & 834 \\
\hline
\end{tabular}

\section{Countries Contribution to Scholarly Output and Citations}

Distribution of papers on phage display across 58 countries is also of interest. The top ten countries published 1621 papers $(73.95 \%)$. Table 7-9 show ranked list of countries according to number of published papers, citations and average citations per paper.

Represented data show that phage display technology has passed into practical stage, as we mentioned above. It is proved by increasing paper count and decreasing number of citations both in absolute terms and in normalized numbers, e.g., citations per paper. Furthermore, applied studies using phage display seem to be developed in Asian countries since they demonstrate growth in publication and citation counts. In European countries, the USA and Australia decrease in research activity was detected compared to initial period in 1990s when basic papers were published giving impetus to rapid growth in the use of phage display technology. Only in Germany and France researchers show sustained interest: Publication activity in these countries lacks of sharp fluctuations.

Switzerland takes leading position according to citations per paper value (9.09 citations) and has the lowest share of uncited papers. At the same time, there has been a reduction of interest to phage display in this country. Switzerland is followed by the Netherlands
(7.87), the United Kingdom (7.35), the USA (7.03), Germany (6.30), Italy (5.49), Australia (4.64), France (4.28), Japan (3.51) and China (2.51).

The most rapid growth in paper count was registered in China that got close to the USA in 2013: 30 papers in China and 31-in the USA. However, Chinese papers are cited significantly more rarely, although Chinese scholarly output is constantly growing. Substantial part of uncited papers (30.04\%) is another interesting fact concerning Chinese studies on phage display. Of note, this value is twice as much as global average index $(13.55 \%)$. This can be explained both by language barrier and probably by lower quality of these papers (Novikov, 2015; Hvistendahl, 2013).

\section{Collaboration}

The considerable part of studies on phage display in different countries has been carried out without any international collaboration. Table 10 shows absolute number of papers and a share of papers published without international collaboration in the top ten countries.

Chinese, Japanese and American scientists are the most independent of international collaboration. In the majority of European countries share of international collaboration ranges from $43 \%$ (Italy) to $56 \%$ (the United Kingdom) due to a number of common scientific programs in Europe. 
Table 8. Distribution of citations over the countries (3-year citation window)

\begin{tabular}{|c|c|c|c|c|}
\hline \multirow[b]{2}{*}{ Country } & \multicolumn{4}{|l|}{ Citation count } \\
\hline & Total & 1993-1999 & 2000-2006 & 2007-2013 \\
\hline$\overline{\mathrm{USA} \downarrow}$ & $5018(44.90 \%)$ & $1701(50.61 \%)$ & $1994(46.29 \%)$ & $1272(37.19 \%)$ \\
\hline China $\uparrow$ & $684(6.12 \%)$ & $7(0.21 \%)$ & $189(4.39 \%)$ & $488(14.27 \%)$ \\
\hline United Kingdom $\downarrow$ & $1301(11.64 \%)$ & $658(19.58 \%)$ & $453(10.52 \%)$ & $157(4.59 \%)$ \\
\hline Germany - & $1039(9.30 \%)$ & $213(6.34 \%)$ & $503(11.68 \%)$ & $323(9.44 \%)$ \\
\hline Japan $\uparrow$ & $439(3.93 \%)$ & $83(2.47 \%)$ & $171(3.97 \%)$ & $185(5.41 \%)$ \\
\hline Netherlands $\downarrow$ & $779(6.97 \%)$ & $272(8.09 \%)$ & $376(8.73 \%)$ & $131(3.83 \%)$ \\
\hline Switzerland $\downarrow$ & $745(6.67 \%)$ & $355(10.56 \%)$ & $299(6.94 \%)$ & $91(2.66 \%)$ \\
\hline Italy $\downarrow$ & $423(3.78 \%)$ & $187(5.56 \%)$ & $152(3.53 \%)$ & $82(2.40 \%)$ \\
\hline France $\uparrow$ & $321(2.87 \%)$ & $55(1.64 \%)$ & $185(4.29 \%)$ & $81(2.37 \%)$ \\
\hline Australia $\downarrow$ & $320(2.86 \%)$ & $111(3.30 \%)$ & $126(2.92 \%)$ & $83(2.43 \%)$ \\
\hline Total $\downarrow$ & 11176 & 3361 & 4308 & 3420 \\
\hline
\end{tabular}

Table 9. Average citations per paper in the top ten countries

\begin{tabular}{|c|c|c|c|c|c|}
\hline \multirow[b]{2}{*}{ Country } & \multicolumn{4}{|c|}{ Citations per paper } & \multirow{2}{*}{$\begin{array}{l}\text { Uncited papers } \\
\text { Total }\end{array}$} \\
\hline & Total & 1993-1999 & 2000-2006 & 2007-2013 & \\
\hline$\overline{\mathrm{USA} \downarrow}$ & 7.03 & 8.68 & 7.10 & 5.51 & $49(6.82 \%)$ \\
\hline China $\uparrow$ & 2.51 & 0.54 & 2.08 & 2.89 & $82(30.04 \%)$ \\
\hline United Kingdom $\downarrow$ & 7.35 & 10.97 & 5.92 & 4.49 & $12(6.78 \%)$ \\
\hline Germany $\downarrow$ & 6.30 & 6.66 & 6.89 & 5.38 & $11(6.66 \%)$ \\
\hline Japan - & 3.51 & 3.95 & 3.64 & 3.26 & $9(7.20 \%)$ \\
\hline Netherlands $\downarrow$ & 7.87 & 9.37 & 7.52 & 6.55 & $5(5.05 \%)$ \\
\hline Switzerland $\downarrow$ & 9.09 & 12.68 & 7.29 & 7.00 & $2(2.44 \%)$ \\
\hline Italy $\downarrow$ & 5.49 & 6.23 & 5.63 & 4.32 & $5(6.49 \%)$ \\
\hline France $\downarrow$ & 4.28 & 5.56 & 4.51 & 3.38 & $3(4.00 \%)$ \\
\hline Australia $\downarrow$ & 4.64 & 6.53 & 4.34 & 3.61 & $2(2.90 \%)$ \\
\hline Total $\downarrow$ & 5.10 & 6.97 & 4.97 & 4.10 & $297(13.55 \%)$ \\
\hline
\end{tabular}

Table 10. Papers without international collaboration

\begin{tabular}{lll}
\hline & Papers without & \\
Country & international collaboration & $\begin{array}{l}\text { Share of papers without } \\
\text { international collaboration (percent) }\end{array}$ \\
\hline USA & 520 & 72.82 \\
China & 230 & 84.24 \\
United Kingdom & 100 & 56.49 \\
Germany & 88 & 53.33 \\
Japan & 94 & 75.20 \\
Netherlands & 99 & 50.50 \\
Switzerland & 82 & 48.78 \\
Italy & 77 & 42.86 \\
France & 75 & 52.00 \\
Australia & 69 & 50.72 \\
\hline
\end{tabular}

Researchers from the United States published the majority of papers with international links-119 collaborative papers with the 9 other top countries. Distribution of the other countries according to the number of collaborative papers is as follows:

- Germany-61 papers/9 countries

- United Kingdom-58 papers/9 countries

- Netherlands-38 papers/8 countries

- China-36 papers/7 countries

- Switzerland-35 papers/7 countries

- Italy-30 papers/ 6 countries
- Australia-25 papers/9 countries

- France-23 papers/7 countries

- Japan-21 papers/6 countries

\section{Phage Display Papers in Scholarly Journals}

Analyzed papers on phage display were published in 638 serials. Table 11 shows the top ten journals published more than $20 \%$ of papers (447 items).

From the middle $2000 \mathrm{~s}$, wider distribution of papers in different journals has been observed. Thus, boundaries of core of journals publishing papers on phage display have begun to dissolve. Growth in the number of papers on phage display was detected only in PLoS One. 
Table 11. The top journals published papers on phage display technology

\begin{tabular}{ll}
\hline Journals & Papers count \\
\hline Journal of immunological methods & $99(4.52 \%)$ \\
Journal of biological chemistry & $61(2.78 \%)$ \\
Journal of molecular biology & $57(2.60 \%)$ \\
Methods in molecular biology clifton N J & $53(2.42 \%)$ \\
Gene & $37(1.69 \%)$ \\
PLoS One & $33(1.51 \%)$ \\
Biochemical and biophysical & $32(1.46 \%)$ \\
research communications & \\
Biotechniques & $27(1.23 \%)$ \\
Biochemistry & $24(1.09 \%)$ \\
Journal of immunology & $24(1.09 \%)$ \\
\hline
\end{tabular}

The majority of highly cited papers were published in journals with high impact factors. Thus, five Nature Publishing Group journals: Nature, Nature Biotechnology, Nature Structural Biology, Nature Protocols and Nature Medicine published 29 papers with 4012 citations from a total value of 50,645 , i.e., $7.92 \%$. Proceedings of the National Academy of Sciences of the United States of America published 17 papers with 1375 citations, i.e., $2.71 \%$. Science journal published three papers (including the first one) cited 2216 times, i.e., $4.38 \%$. Thus, those 49 papers $(2.24 \%)$ have been cited 7603 times (15.01\%). Papers published in the top 10 journals (Table 11) have been cited 10,809 times $(21.34 \%)$. This value corresponds to share of phage display papers in these journals $(20.39 \%)$.

\section{Conclusion}

This paper enables us to trace the history of phage display studies through the last 30 years in terms of bibliometrics. Researchers published 2194 papers in 638 serials registered in Scopus database. The USA, China, Great Britain, Germany, Japan, the Netherlands, Switzerland, Italy, France and Australia were the most productive countries and accounted for $74 \%$ of scholarly output. In 1993-2000 there was the most significant increase in the number of papers, registering $27 \%$ per year. In the last 15 years slowdown in the growth was observed. Research activity was shifted from the USA and the European countries to Asian research organization. However, Western papers continue to obtain the majority of citations. Distribution of journals publishing studies on phage display is increasing; therefore, now we can observe that the core of journals with papers on phage display is dissolving its boundaries.

\section{Funding Information}

This study was supported by the Ministry of Education and Science of the Russian Federation (No. 303 Grant).

\section{Author's Contributions}

All authors have read and approved the final manuscript.

Alexander Ilyichev and Larisa Karpenko: Analyzed and discussed obtained results.

Vadim Gureyev: Collected and processed bibliometric data and wrote the manuscript.

Nikolay Mazov: Designed bibliometric study, structured and planned the paper.

\section{Ethics}

The paper contains unpublished material. The corresponding author confirms that there were no ethical issues concerning the manuscript.

\section{References}

Archambault, É., É. Vignola-Gagné, G. Côté, V. Larivière and Y. Gingras, 2005. Welcome to the linguistic warp zone: Benchmarking scientific output in the social sciences and humanities. Proceedings of the 10th Biennial International Conference of the International Society for Scientometrics and Informetrics, (SSI' 05), Stockholm, pp: 1-11.

Cwirla, S.E., E.A. Peters, R.W. Barrett and W.J. Dower, 1990. Peptides on phage: A vast library of peptides for identifying ligands. Proc. National Acad. Sci. United States Am., 87: 6378-6382. DOI: $10.1073 /$ pnas.87.16.6378

Devlin, J.J., L.C. Panganiban and P.E. Devlin, 1990. Random peptide libraries: A source of specific protein binding molecules. Science, 249: 404-406. DOI: 10.1126/science. 2143033

Felici, F., L. Castagnoli, A. Musacchio, R. Jappelli and G. Cesareni, 1991. Selection of antibody ligands from a large library of oligopeptides expressed on a multivalent exposition vector. J. Molecular Biol., 222: 301-310. DOI: 10.1016/0022-2836(91)90213-P

Gupta, B.M., K.K. Mueen Ahmed, R. Gupta and R. Tiwari, 2015. World camel research: A scientometric assessment, 2003-2012. Scientometrics, 102: 957-975. DOI: $10.1007 / \mathrm{s} 11192-014-1405-5$

Gureyev, V.N. and N.A. Mazov, 2013. Detection of information requirements of researchers using bibliometric analyses to identify target journals. Inform. Technol. Librar., 32: 66-77. DOI: $10.6017 /$ ital.v32i4.3421

Hvistendahl, M., 2013. China's publication bazaar. Science, 342: 1035-1039. DOI: $10.1126 /$ science. 342.6162 .1035 
Il'ichev, A.A., O.O. Minenkova, S.I. Tat'kov, N.N. Karpyshev and A.M. Eroshkin et al., 1989. Production of a viable variant of the M13 phage with a foreign peptide inserted into the basic coat protein. Doklady Akademii Nauk SSSR, 307: 481-483. PMID: 2806065

Leydesdorff, L. and S. Milojević, 2014. The citation impact of German sociology journals: Some problems with the use of scientometric indicators in journal and research evaluations. Soc. Sci. Res. Netw., 66: 193-204.

LRJIS, 2014. List of Russian journals indexed in Scopus.

Novikov, D.A., 2015. Compete by Hirsch's? Vysshee obrazovanie v Rossii.

Parmley, S.F. and G.P. Smith, 1988. Antibody-selectable filamentous FD phage vectors: Affinity purification of target genes. Gene, 73: 305-318.

DOI: $10.1016 / 0378-1119(88) 90495-7$
RSCI, 2015. Russian science citation index.

Scopus, 2015. www.scopus.com.

Scott, J.K. and G.P. Smith, 1990. Searching for peptide ligands with an epitope library. Science, 249: 386-390. DOI: 10.1126/science. 1696028

Smith, G.P. and V.A. Petrenko, 1997. Phage display. Chem. Rev., 97: 391-410. DOI: 10.1021/cr960065d

Smith, G.P., 1985. Filamentous fusion phage: Novel expression vectors that display cloned antigens on the virion surface. Science, 228: 1315-1317.

DOI: $10.1126 /$ science. 4001944 